\title{
PRODUÇÃO DE PROTEASES POR ASPERGILLUS ORYZAE EM FERMENTAÇÃO SEMI-SÓLIDA UTILIZANDO FARELO DE TRIGO E CANOLA
}

\author{
D. B. ANDRADE ${ }^{1}$, G. A. S. PINTO ${ }^{2}$ e A. C. FREITAS ${ }^{1}$ \\ ${ }^{1}$ Universidade Federal do Maranhão, Departamento de Engenharia de Alimentos \\ ${ }^{2}$ Embrapa Agroindústria Tropical - CNPAT \\ E-mail para contato: engdiva@hotmail.com
}

RESUMO- Fermentação semi-sólida aplica-se ao processo de crescimento de micro-organismos em substratos sólidos sem a presença de água livre. Nesse contexto, o objetivo deste trabalho foi avaliar o uso do farelo de trigo e torta de canola em cultivo semi-sólido com diferentes linhagens de Aspergillus oryzae para produção de proteases. As linhagens estudadas foram CCBP001, NRRL 2217, NRRL 2220, NRRL 1694 e NRRL 5590. Todas as linhagens produziram protease, a maior produção foi identificada quando utilizou-se a torta de canola apresentando atividade de

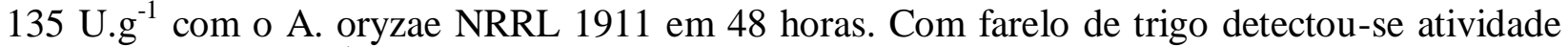
máxima de $121{\mathrm{U} . g^{-1}}^{\text {em }} 48$ horas com a linhagem NRRL 2220. Dessa forma, o cultivo semisólido é um potencial para a produção de protease empregando torta de canola e farelo de trigo como substrato.

\section{INTRODUÇÃO}

A fermentação semi-sólida desempenha um papel de destaque no aproveitamento de resíduos sólidos, pois consiste em uma técnica de crescimento de micro-organismos sobre e no interior de partículas porosas úmidas na qual o conteúdo de líquido contido na matriz sólida deve ser mantido em valores de atividade de água que assegure o conveniente crescimento e metabolismo celular, mas que não exceda a capacidade máxima de retenção de água na matriz (PALMA, 2003).

Dentre os principais produtos da fermentação semi-sólida figuram as enzimas, as quais são produzidas comercialmente principalmente a partir de micro-organismos, devido em grande parte à diversidade dos mesmos, facilidade e controle operacional e maior rendimento em relação aos processos extrativos de tecidos animais e vegetais. Os fungos filamentosos destacam-se na produção enzimática, pois são mais adaptáveis ao processo semi-sólido, além de crescerem com pouca água, a sua forma de crescimento, por meio de hifas, favorecer o crescimento no meio (MACIEL, 2006).

Diversos grupos de micro-organismos são capazes de produzir proteases por processos de fermentação dependendo do tipo de substrato. As proteases podem ser empregadas em vários ramos industriais, dentre eles pode-se citar: Panificação para hidrolisar o glúten, indústria de carne no processo de amaciamento, indústria de queijos no desenvolvimento de sabor, aroma e textura dos mesmos. Além disso, podem ser utilizadas em formulações para uso hospitalar para digerir e dissolver 
resíduos orgânicos (ROCHA, 2010).

Neste contexto, este trabalho propõe a utilização da torta de canola e farelo de trigo como substrato para produção de proteases por fermentação semi-sólida assim como, avaliar diferentes a linhagens de Aspergillus.

\section{MATERIAIS E MÉTODOS}

\subsection{Matéria-Prima}

Utilizou-se farelo de trigo e torta de canola para obter os extratos enzimáticos. A torta de canola foi cedida gentilmente pela Embrapa Agroindústria Tropical (CNPAT) - Fortaleza, Ceará. O farelo de trigo foi adquirido no comercio local.

\subsection{Meios de fermentação}

Para umidificar a torta de canola utilizou-se uma proporção de $100 \mathrm{~g}$ de farelo para $40 \mathrm{~mL}$ de água destilada. Já para o farelo de trigo por ser muito higroscópico utilizou-se a proporção de $100 \mathrm{~g}$ de farelo para $125 \mathrm{~mL}$ de água destilada. Estas proporções foram determinadas por Freitas (2013).

\subsection{Micro-organismos}

As linhagens de fungos filamentosos do gênero Aspergillus utilizadas, descritas na Tabela 1 pertencem à coleção de trabalho do Laboratório de Bioprocessos da Embrapa Agroindústria Tropical e da Coleção de Culturas North Regional Research Laboratory (NRRL) do departamento de agricultura dos Estados Unidos.

Tabela 1- Linhagem dos fungos do gênero Aspergillus

\begin{tabular}{cccc}
\hline Código & Espécie & Origem & Instituição \\
\hline CCBP 001 & A.oryzae & Desconhecida & CNPAT \\
NRRL 2220 & A.oryzae & NRRL & CNPAT \\
NRRL 5590 & A.oryzae & NRRL & CNPAT \\
NRRL 1911 & A.oryzae & NRRL & CNPAT \\
NRRL 2217 & A.oryzae & NRRL & CNPAT \\
NRRL 1694 & A.oryzae & NRRL & CNPAT \\
\hline
\end{tabular}

CCBP-Coleções de culturas Bioprocessos; NRRL- North Regional Research Laboratory

\subsubsection{Manutenção das culturas}

Esporos de cada linhagem foram assepticamente transferidos para tubos com rosca, contendo solo estéril e estocados a $-18^{\circ} \mathrm{C}$. 


\section{9 a 22 de outubro de 2014 \\ Florianópolis/SC}

\subsubsection{Ativação das culturas}

Os esporos armazenados em solo estéril a $-18{ }^{\circ} \mathrm{C}$ foram transferidos para um ágar batata dextrose inclinado previamente esterilizado a $121{ }^{\circ} \mathrm{C}$ por 15 minutos. e incubadas a $30^{\circ} \mathrm{C}$ por 7 dias em estufa (primeiro repique). No segundo repique, os fungos do primeiro repique foram transferidos para um novo ágar batata dextrose inclinado e incubadas a $30^{\circ} \mathrm{C}$ por 7 dias em estufa.

Para a ativação das culturas os esporos do segundo repique foram transferidos para um meio com farelo de trigo. Para tanto preparou-se um meio constituído de $10,0 \mathrm{~g}$ de farelo de trigo e $4 \mathrm{~mL}$ de uma solução $1,7 \%(\mathrm{~m} / \mathrm{v}) \mathrm{NaHPO}_{4}$ e 2,0\% (m/v) de $\left(\mathrm{NH}_{4}\right)_{2} \mathrm{SO}_{4}$. O meio foi esterilizado a 1 atm a $121^{\circ} \mathrm{C}$ por $15 \mathrm{~min}$, em seguida as linhagens foram inoculas e incubadas a $30^{\circ} \mathrm{C}$ por 7 dias em estufa (FREITAS, 2013).

\subsection{Fermentação semi-sólida em frasco Erlenmeyer}

Os ensaios foram conduzidos em frasco Erlenmeyer $500 \mathrm{~mL}$ com $40 \mathrm{~g}$ do meio umidificado (proporção 4:10) e esterilizados a $121{ }^{\circ} \mathrm{C}$ por $15 \mathrm{~min}$. As fermentações foram conduzidas a $30{ }^{\circ} \mathrm{C}$ durante 96 horas. Os meios foram inoculados com suspensão de esporos e incubados em estufa a 30 ${ }^{\circ} \mathrm{C}$. Amostras foram retiradas a cada 24 horas.

\subsection{Obtenção dos Extratos Enzimáticos}

O extrato enzimático foi obtido pela adição de tampão acetato de sódio $200 \mathrm{mM} \mathrm{pH} \mathrm{5,0} \mathrm{na}$ razão de $100 \mathrm{~mL}$ de solução para $40 \mathrm{~g}$ de meio fermentado, permanecendo incubado em estufa a 30 ${ }^{\circ} \mathrm{C}$ por um período de 1 hora, filtrada com papel de filtro qualitativo e utilizada na determinação da atividade enzimática (FREITAS, 2013).

\subsection{Atividade enzimática de protease}

A atividade proteolítica foi determinada segundo a metodologia de Charney e Tomarelli (1947), utilizando azocaseína como substrato e ácido tricloroacético como agente de precipitação. A formação do composto cromóforo ocorreu pela adição de solução de hidróxido de potássio $5 \mathrm{~N}$. A leitura da intensidade de cor ocorreu a $428 \mathrm{~nm}$. Uma unidade de atividade proteásica foi definida como a quantidade de enzima que produz uma diferença de 0,01 de absorbância por minuto de reação entre o branco reacional e a amostra nas condições de ensaio.

\section{RESULTADOS E DISCUSSÕES}

A Figura 1 apresenta os resultados da produção de proteases por diferentes linhagens de Aspergillus oryzae nas fermentações utilizando a torta de canola como substrato. Todas as linhagens de Aspergillus oryzae estudadas produziram proteases. A maior atividade de protease ocorreu em 72

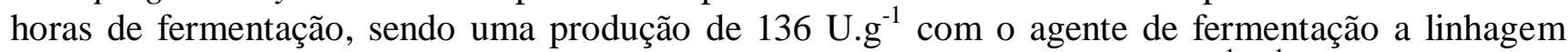
NRRL1911. Sendo a maior produtividade para esta linhagem de $2,7 \mathrm{U} \cdot \mathrm{g}^{-1} \cdot \mathrm{h}^{-1}$ em 48 horas de fermentação (Figura 2), onde detectou-se uma atividade de 132,5 U.g ${ }^{-1}$. A produtividade de protease 
está relacionada com a quantidade de protease que foi produzida em cada tempo de fermentação.

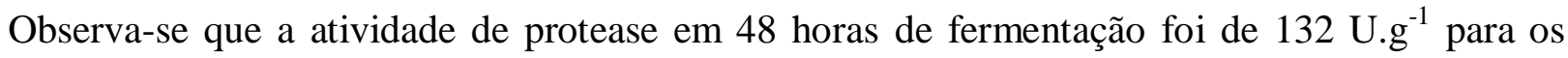
experimentos utilizando as linhagens CCBP 001 e NRRL 1911, no entanto, a produção do primeiro decresce ao longo do processo fermentativo, enquanto o segundo mantém sua produção constante entre 72 e 96 horas de processo fermentação.

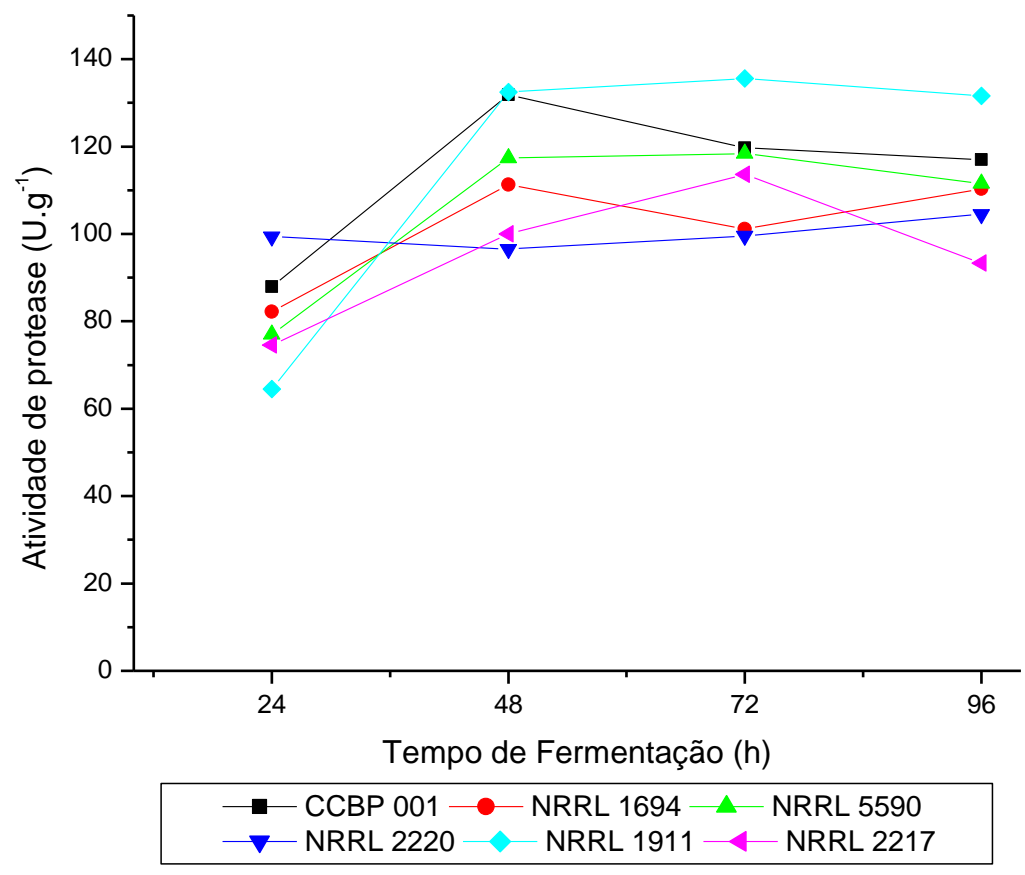

Figura 1- Atividade de protease para diferentes linhagens de Aspergillus oryzae em torta de canola

A Figura 2 apresenta a produtividade de proteases das linhagens avaliadas durante o tempo fermentativo. A maior produtividade foi detectada em 24 horas pela linhagem NRRL 2220,4,1 U.g ${ }^{1} \cdot \mathrm{h}^{-1}$, e atividade equivalente a $99 \mathrm{U} \cdot \mathrm{g}^{-1}$, com atividade constante ao longo do processo fermentativo. A maior produtividade para todas as linhagens encontra-se no menor tempo amostral da fermentação e a menor em 96 horas. Perfil não observado para a linhagem NRRL 1911 que apresentou a maior produtividade em 48 horas. 


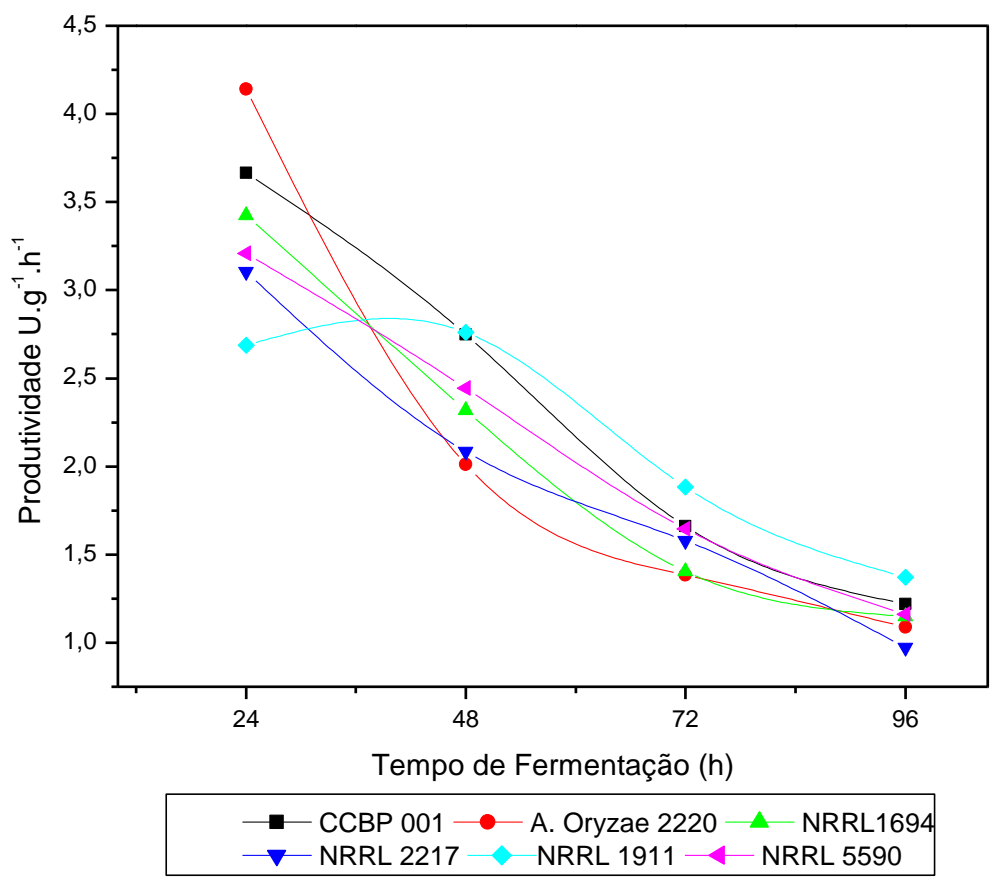

Figura 2- Produtividade de proteases pelas diversas linhagens de Aspergillus oryzae em torta de canola

Freitas (2009) realizou um estudo com linhagens de A. oryzae e A. niger utilizando torta de canola como substrato. Verificou-se que a maior atividade foi obtida em 48 horas com Aspergillus oryzae IV, sendo de aproximadamente $60 \mathrm{U.g}^{-1}$ durante todo o processo fermentativo. Em 24 horas detectou-se $57 \mathrm{U} \cdot \mathrm{g}^{-1}$ obtendo uma produtividade de $2,3 \mathrm{U} \cdot \mathrm{g}^{-1} \cdot \mathrm{h}^{-1}$. No presente estudo, a linhagem $A$. oryzae IV apresentou o segundo melhor desempenho na produção de proteases, com atividade

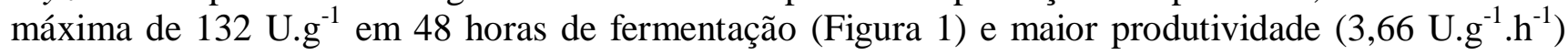
ocorreu em 24 horas de fermentação (Figura 2).

Murthy e Naidu (2010) estudaram a fermentação semi-sólida com Aspergillus oryzae CFR 305 como potencial para a produção de proteases. Cascas de café de diversos cultivares foram utilizados como substratos. A casca do café cereja com umidade inicial de $50 \%$ a $27{ }^{\circ} \mathrm{C}$ incubada por 5 dias dentre os diferentes substratos mostrou-se a mais eficiente na produção da enzima com atividade de $7.539 \mathrm{U} / \mathrm{gss}$. A casca de café mostrou ser um ótimo substrato para o processo semi-sólido utilizando fungos filamentosos em 5 dias de fermentação, assim como a torta de canola utilizada nesse estudo, porém a maior atividade de proteases $\left(136{\mathrm{U} . \mathrm{g}^{-1}}^{-1}\right)$ em torta de canola foi em 3 dias de fermentação (72 horas).

As atividades de proteases em farelo de trigo são apresentadas na Figura 3. Observa-se que 
todas as linhagens estudadas produziram proteases, a maior atividade de protease, equivalente a 121

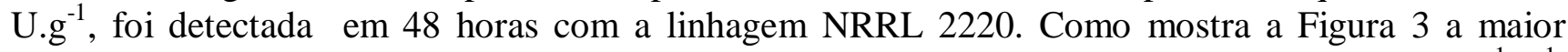
produtividade para esta linhagem foi em 48 horas com uma produtividade equivalente a $2,52 \mathrm{U} \cdot \mathrm{g}^{-1} \cdot \mathrm{h}^{-1}$, a produção de protease por esta linhagem apresentou um rápido crescimento em 48 horas, mas em 72 e 96 horas de fermentação esta produção sofreu um forte declínio.

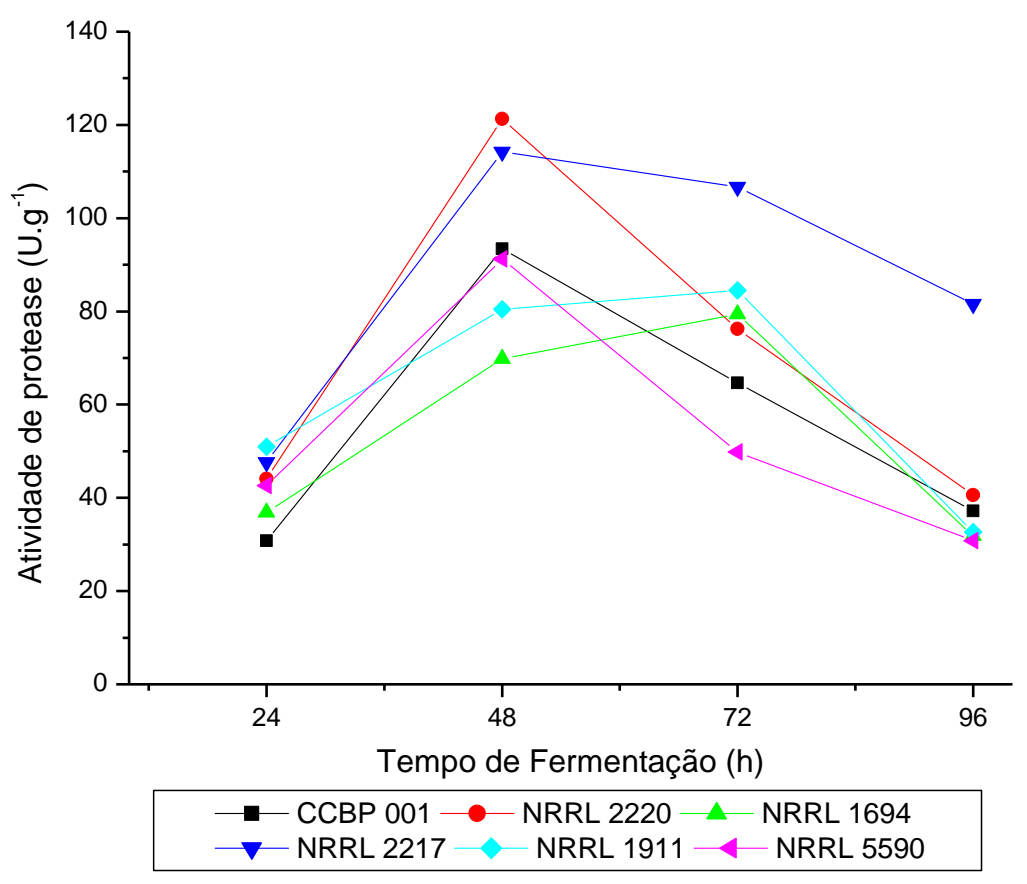

Figura 3- Atividade de protease pelas diferentes linhagens de Aspergillus oryzae em farelo de trigo como substrato

Houve um declínio na atividade de protease no decorrer do processo fermentativo. No entanto, acredita-se que esta queda na produção de próteses seja em razão do consumo da enzima pelo fungo, para quebrar as cadeias de aminoácidos facilmente disponível no meio. Dentre as linhagens estudadas aquela que apresentou uma menor queda na atividade de proteases foi a linhagem NRRL 2217.

A Figura 4 apresenta a produtividade de proteases no decorrer do processo fermentativo em farelo de trigo. A produtividade máxima foi de $2,52 \mathrm{U} \cdot \mathrm{g}^{-1} \cdot \mathrm{h}^{-1} \mathrm{com}$ a linhagem de NRRL 2220 em 48 horas de fermentação e atividade de $121 \mathrm{U}_{\mathrm{g}}{ }^{-1}$. Esta linhagem foi a que apresentou maior produtividade de protease para a torta de canola em 24 horas.

A atividade máxima obtida pela linhagem CCBP 001 ocorreu quando utilizou-se o farelo de trigo como substrato com $93{\mathrm{U} . g^{-1}}^{\mathrm{em}} 78$ horas de fermentação (Figura 3). No entanto, Freitas (2013) obteve melhores resultados de atividade de protease para o farelo de trigo, em seu estudo sobre a influência da quantidade de água em diversos substratos para produção de proteases (torta de canola, 
torta de girassol, farelo de trigo, película da casca da castanha de caju, farelo de soja e farelo de algodão) em fermentação semi-sólida com Aspergillus oryzae IV. O farelo de trigo manteve uma produção crescente à medida que as porções de água eram adicionadas, alcançando máxima produção em 24horas de fermentação, com 211,2 U.g ${ }^{-1}$ de protease quando o meio formulado continha $125 \mathrm{~mL}$ de água para cada $100 \mathrm{~g}$ de substrato.

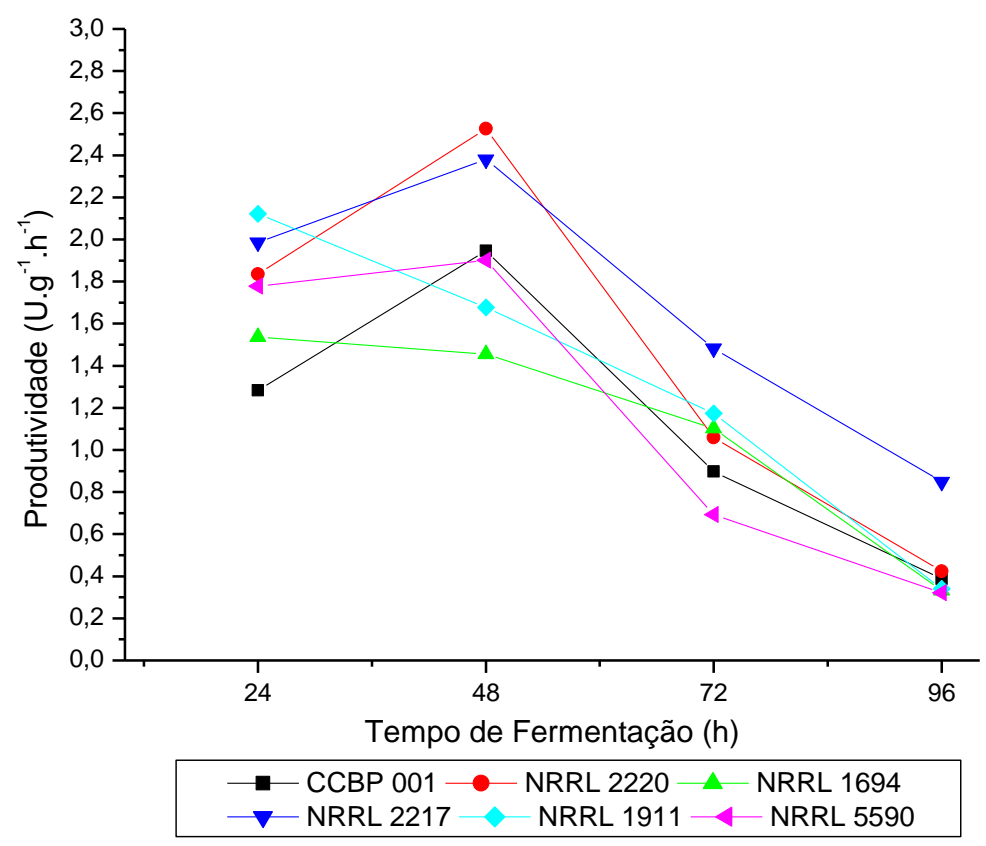

Figura 4- Produtividade de proteases pelas diversas linhagens de Aspergillus oryzae em farelo de trigo

Resultados inferiores de atividade de protease em farelo de trigo foram encontrados por Sandhya et al. (2005). Ao realizarem um estudo comparativo para avaliaram a viabilidade da fermentação submersa e da fermentação semi-sólida na produção de uma protease neutra, com fungos de diferentes linhagens de Aspergillus oryzae e Penicillium, utilizando resíduos agroindustriais (farelo de trigo, casca de arroz, farelo de arroz, torta de óleo de coco, torta dendê, torta de óleo de gergelim e torta de azeite) como substrato para a FSS e FSM. Os autores verificaram que a melhor linhagem testada para a produção de protease neutra foi $A$. oryzae NRRL 1808. Em ambos os sistemas de fermentação, o farelo de trigo foi o melhor substrato. Os melhores resultados para FSS foram obtidos com teor de umidade inicial de $43,6 \%$, quando inoculados com $1 \mathrm{~mL}$ de suspensão de esporos $\left(10^{8}\right.$

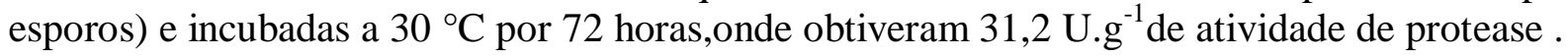




\section{CONCLUSÃO}

Dessa forma, todas as linhagens estudadas produziram proteases em cultivo semi-sólido empregando torta de canola e farelo de trigo como substratos. A torta de canola nas condições estudadas mostrou-se mais eficiente com a linhagem de A. oryzae NRRL 1911.

\section{REFERÊNCIAS}

CHARNEY, J.; TOMARELLI, R.M.A colorimetric method for the determination of theproteolytic activity of duodenal juice.J. of Bio.Chem.v.170, n. 23, p. 501-505, 1947.

FREITAS, A.C. Produção de extrato enzimático proteolítico por fermentação semi-sólida em reator instrumentado. Tese (Doutorado)- Curso de Pós-Graduação em Engenharia Química, Universidade Federal do Ceará, 2013.

KUMAR, S.; SHARMA, N.S.; SAHARAN, M.R.; SINGH, R. Extracellularacid protease from Rhizopus oryzae: purification and characterization. Proc. Biochem. v. 40, n. 5, p. 1701-1705 2005.

MACIEL, G.M. Desenvolvimento de bioprocesso para produção de xilanases por fermentação no estado sólido utilizando bagaço de cana de açúcar e farelo de soja. Dissertação (Mestrado)-Processos Biotecnológicos, Universidade Federal do Paraná, Curitiba, 2006.

MURTHY, P.S.; NAIDU, M.M. Protease productionby Aspergillus oryzae in solid-state fermentation utilizing coffee by-products. W. App.Scien. J. v.8 pp 199-205, 2010.

PALMA, M. B. Produção de xilanases por Thermoascusaurantiacus em cultivo em estado sólido.Tese (Doutorado em Engenharia Química), - Centro Tecnológico, Curso de Pós Graduação em Engenharia Química, Universidade Federal de Santa Catarina, Florianópolis, 2003.

ROCHA, C.P. Otimização da Produção de Enzimas por Aspergillus niger em Fermentação em Estado Sólido. Dissertação (mestrado)- Pós-Graduação em Engenharia Química, Universidade Federal de Uberlândia, Uberlândia, 2010.

SANT'ANA, L. F. R. Nutritive value and antinutritional factors ofmultimixtures used as alternative Foods. Braz.J.of Food Techno.,v.3, p.129-135, 2000.

SANDHYA, C.; SUMANTHA, A.; SZAKACS, G.; PANDEY, A. Comparative evaluation of neutral protease production by Aspergillus oryzae in submerged and solid-state fermentation. P. Biochem., v. 40, p. 2689-2694, 2005. 